Understanding gender differences in older people's attitudes towards life-prolonging medical technologies

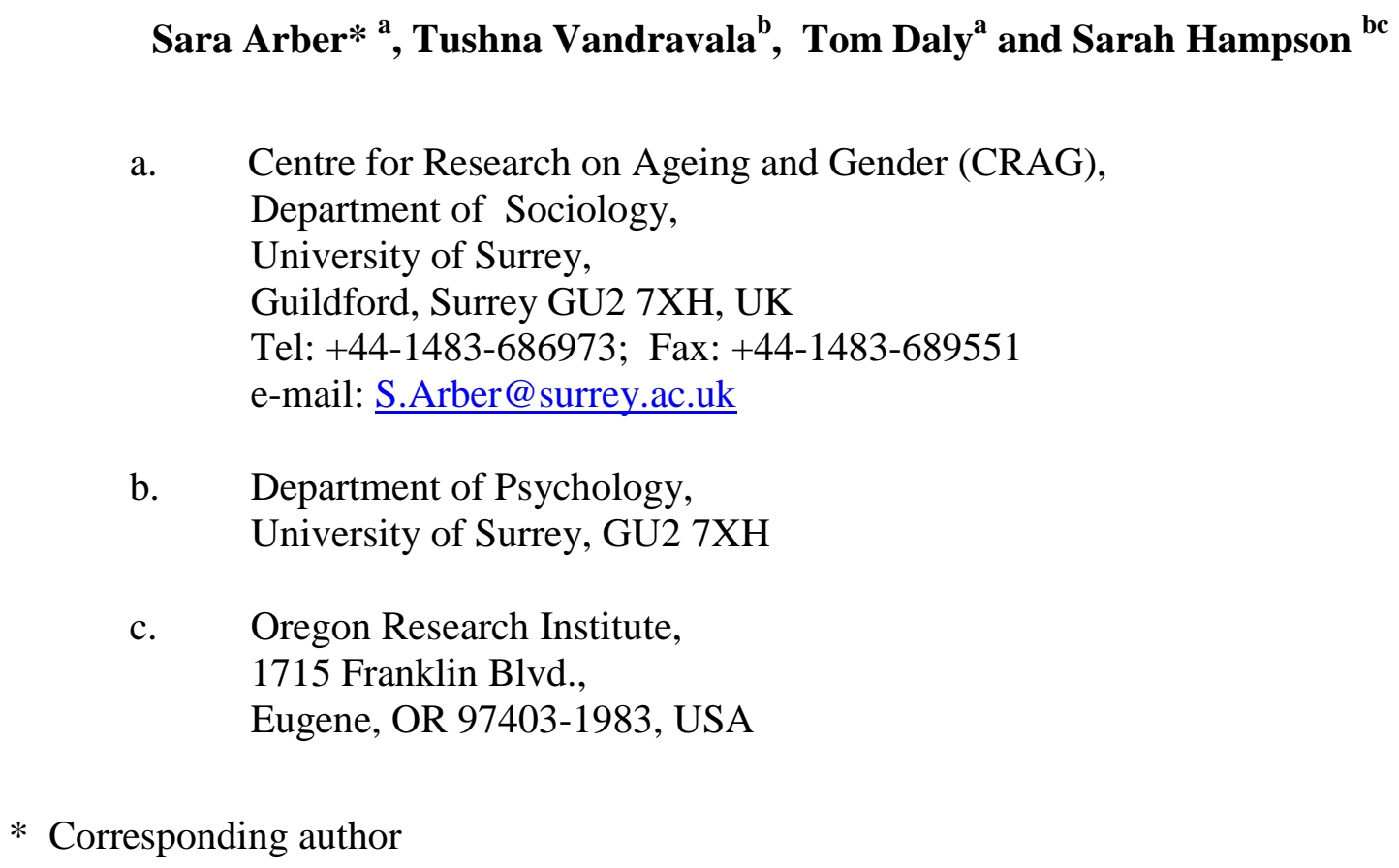

Published in: $\quad$ Journal of Aging Studies (2008), vol 22, no 4, pp 366-375.

Special Issue edited by John Vincent, Emmanuelle Tulle and John Bond on 'The control of ageing: technologies, practices and conflicts' 


\title{
Understanding gender differences in older people's attitudes towards life-prolonging medical technologies
}

\begin{abstract}
The power of medical technologies to extend the final stages of life has heightened the need to understand what factors influence older people's wish to use such medical technologies. We analyse gender differences in such views, based on audio-recorded interviews with 33 men and 36 women (aged 65-93) in south-east England. Older women were twice as likely as men to oppose using medical technologies to extend life. More older women voiced 'other-oriented' reasons for their opposition, particularly not wanting to be a burden on others. Older men's attitudes were primarily 'self-oriented', reflecting a concern to stay alive for as long as possible, with fewer expressing concern about consequences for others. Women's greater life course involvement in caring and empathising with the wishes and concerns of others underlay these gender differences. Thus, women were 'performing gender' by putting others before themselves, even at this critical juncture in their lives.
\end{abstract}

\section{Keywords}

Gender, Life-prolonging medical technologies, Cardiopulmonary resuscitation, Older people 


\section{Introduction}

Hitherto there has been a separation between the concerns of writers on anti-aging medicine (cf. Vincent 2006, papers in this special issue), and research regarding lifeprolonging medical technologies. Medical technologies are increasingly available to extend the final stages of life. However, controversies abound over using technologies, such as cardiopulmonary resuscitation, ventilation and artificial feeding, which may simultaneously extend life, but can also result in a poor quality of the end stages of life and dying with lack of dignity.

Both the anti-aging literature and research on decision-making at the end-of-life implicitly subscribe to a rhetoric of the choices of atomised individuals about use of anti-aging medicines or life-prolonging medical technologies. Within the anti-aging literature concerns are raised about social inequalities, particularly how wealth and income may facilitate or prevent access to life enhancing technologies (Vincent 2006). Both fields have neglected to what extent the 'choices' of individuals may be bounded by social or cultural factors, including how gender may be associated with fundamental values and attitudes related to life extension. Since older people are the primary subjects of life-prolonging medical technologies, it is particularly salient to hear their voices and preferences, especially within a societal context of freely available health care, such as the British National Health Service. By using interviews to closely analyse the views of older people about life-prolonging medical technologies, this paper complements the papers by Settersen et al. and by Mykytyn (in this issue) which use qualitative interviews to examine the perspectives of scientists engaged in biogerontological research and anti-aging practitioners respectively.

A health policy concern over recent years has been to increase control and autonomy over decision-making at the end-of-life, for example by encouraging use of 'Do-NotAttempt-to-Resuscitate' (DNAR) orders and Living Wills or Advance Directives (Duffield and Podzansky 1996, Rodriguez and Young 2006, Carr and Khodyakov 2007). This medical policy development has conceptualised patients as independent and autonomous subjects, rather than as gendered persons. A neglected issue is to what extent an individual's expressed wishes about end-of-life care are influenced by their social characteristics, such as their gender, and their life course experiences. 
In the UK, the British Medical Association (2001) has introduced guidelines related to DNAR orders (that is, an advance decision that cardiopulmonary resuscitation (CPR) should not be attempted). Under these guidelines the ultimate responsibility for deciding whether to attempt resuscitation lies with the doctor in charge of the patient's care. The guidelines specify that the doctor should have ascertained the wishes of the patient in advance. However, this is fraught with difficulties where patients are hospitalised in a critical condition, or where the patient lacks the medical capacity to indicate their wishes. In these circumstances, the alternatives are either that the patient has previously specified their wishes through an 'Advance Directive' or a 'Living Will', or that the patient's family members are consulted and represent the 'interests' of the patient.

Despite the increasing importance of NHS guidelines that staff should involve patients and their families in decisions about resuscitation, there has been little sociological research in this area. Indeed, Conroy et al. (2006: 480) state 'This area is under-researched and relatively little is known about the attitudes towards cardiopulmonary resuscitation among frail elderly people'.

\section{Gender and attitudes to life-prolonging technologies}

Most studies of the attitudes of older people to life-prolonging medical technologies have examined use of CPR among hospitalised patients. Although gender has not been a focus of these studies, many have noted gender differences in attitudes. For example, a UK study of 134 patients from geriatric assessment wards (average age 81 ), found $42 \%$ wanted resuscitation for themselves, with substantially more men in favour than women (67\% versus 24\%) (Gunasekara et al.1986). Larger US studies have also noted this gender difference. The SUPPORT (Study to Understand Prognosis and Preferences for Outcomes and Risks of Treatments) Project interviewed 1,650 patients (mean age 62) from 5 geographically diverse acute-care medical centres, finding that more women than men (34\% and $23 \%$ respectively) did not want resuscitation (Phillips et al.1996). Other US studies of hospitalised patients report that men were more likely to desire cardiopulmonary resuscitation than women (Lo et al.1985, Schonwetter et al.1994), although this gender difference did not reach statistical significance in Malloy et al. (1992). Related research on desire to live 
longer towards the end of life has also found gender differences. Relatives, of 3936 people who had died in the previous year, reported that $28 \%$ of the women who had died, compared to $19.5 \%$ of the men, had said they wanted to die sooner, and significantly more women were said to have wanted euthanasia (Seale and Addington-Hall 1995).

Because of the difficulties of discussing life prolonging medical technologies once patients are hospitalised, it may be preferable to gauge the attitudes of older people living in the community. Fewer studies have examined attitudes of healthy older people towards use of life-sustaining medical technologies. Carmel's (1999) study on attitudes of an Israeli sample of 987 people aged 70+ to hypothetical scenarios regarding three life-sustaining technologies, found higher levels of support for $\mathrm{CPR}$, followed by mechanical ventilation and lowest support for artificial tube feeding. Women were less likely to want treatments to prolong life when asked about these hypothetical illness conditions (Carmel 2001). Ditto et al. (2003) asked a US sample of 322 older adults about their preferences for life-sustaining treatments related to nine hypothetical scenarios representing various degrees of severity of condition and prognosis, finding that men wanted significantly more treatment than women in seven of the nine scenarios (with a non-significant gender difference in the remaining two scenarios). They conclude that 'This gender difference in desire for life-sustaining treatment was a consistent trend found in the present study and replicates past research' (Ditto et al. 2003: 613-4). However, they do not consider the reasons or implications of the gender difference. Seymour et al. (2004: 58) also comment that these consistent gender differences 'are poorly understood'.

Attitudinal research about end-of-life care and preferences for life-sustaining interventions is primarily psychological, with little attempt to address sociological issues or what underlies these findings of gender difference, in terms of gender roles and relationships and 'doing gender' (West and Zimmerman 1987). It is important to recognise that gender is not something that is ascribed to a person, but is continually produced and negotiated through actions and interactions and may be implicated in such a fundamental issue as an older person's attitudes towards treatment at the end of their own life. 
Research on end-of-life decision-making primarily casts patients as autonomous individual decision-makers. However, women and men may draw on different aspects of their identities, life experiences and knowledge base when considering the complexity of issues associated with attitudes about end-of-life care.

This paper illustrates the ways in which one social factor, gender, influences cultural understandings of using life-prolonging technologies, focusing particularly on older individual's attitudes about the desirability of using such technologies for themselves at their end of life. Following an outline of the methods employed in this study, gender differences in older people's attitudes towards use of life-prolonging medical technologies are examined. We then provide an indepth analysis of the discourses of older men and women about use of medical technologies to extend end of life in order to foreground the cultural meanings underlying observed gender differences.

\section{Methods}

The paper analyses data collected as part of a larger UK study on the attitudes and values of healthy older people and their confidants regarding the use of life-sustaining medical technologies (Vandrevala et al. 2006, Garnett et al. 2008). Older men and women living in the community in south-east England were recruited from four general practices with socio-economically diverse populations. General practitioners were asked to send letters to equal numbers of male and female patients aged 65-69, 70-74, 75-79 and 80 and over, in order to recruit approximately equal numbers of men and women in these four age groups. A total of 312 letters were sent out by general practices. Each of the four general practices made a random selection from their patient database to select 72 patients ( 9 male and 9 female in each of the four age groups). An additional 24 letters ( 3 in each age-sex group) were sent out by the practice in the least affluent area in order to increase the representation of less advantaged older people.

The letters invited participation in a study seeking patients' views on health care issues for older people, asking them to reply by returning a pro forma with their contact details if they were interested. Older people expressing an interest in the study were telephoned. The research was described as investigating older people's views 
about the challenges of growing old and their views about health care, including their thoughts and preferences about life-prolonging medical technologies and how they wished to be involved in their medical decision-making in the later stages of life. The eligibility criteria were: ability to read and comprehend English, live in the community, and not suffer from dementia, any cognitive disability or depression. Some older people who volunteered were not interviewed because they did not fulfil these eligibility criteria, others had died or moved away. In addition, some willing participants were not interviewed because sufficient numbers had been interviewed within specified age-sex categories.

Interviews were conducted with 69 people over age 65. The response rate was 30\%, after excluding those who were ineligible, and those who were not interviewed because an age-sex category was complete. The sample of older participants comprised 36 women (52\%) and 33 men (48\%), with an age range of 65 to 93 years, and a mean age of 72.5 years.

Ethical approval for the research was granted by the South West Surrey Research Ethics Committee and by the University of Surrey Advisory Committee on Ethics. Prior to the interview, the aims of the research were repeated and discussed with participants, who were assured of anonymity and confidentiality. Participants gave their written informed consent and it was explained that they could withdraw from the interview at any time. Audio-recorded semi-structured interviews took place in the participants' homes in 2003, lasting approximately 45 minutes. They were conducted either by the second or third author (a woman in her late 20s and a man in his mid 60s respectively). The audio-recorded interviews were listened to by research team members and no difference in the quality of the interviews was found between the two interviewers. Care was taken to ensure that participants were not adversely affected by the sensitivity of issues discussed during the interview, and a period of time was spent in more general informal conversation after the interview, providing reassurance where appropriate. At the end of the interview, participants were given an information sheet on CPR and a list of organisations that could provide help, information or counselling. They were also given the option of a follow-up telephone call the following day, and were provided with the researcher's contact information. 


\section{Measures of attitudes to life-prolonging technologies}

Following general socio-demographic questions, the interviewer introduced the topic of life-prolonging measures by telling participants that advances in medical technologies have made it possible to keep people alive for longer. Participants were asked for their views or thoughts about these 'life prolonging medical technologies that are used to increase life span at the final stages of life'. The interviewer listened to the verbatim responses and recorded these into four categories: 'opposed', 'accept', 'conflicting views' or 'under certain circumstances'. The audio-recordings were checked to ensure that verbatim responses were coded as 'opposed' or 'accept' only when these were unequivocally stated by the respondent. Where respondents provided more information, or qualified their responses in some way, they were coded in the other two categories.

Respondents' attitudes were later explored in relation to 3 specific life-prolonging medical technologies: use of ventilator machines (to assist breathing), artificial (tube) feeding and Cardiopulmonary Resuscitation (CPR). They were asked to rate the acceptability of each procedure on a 5 point scale ranging from 1= 'highly opposed' to $5=$ 'very acceptable', and to give reasons for their score, which were recorded verbatim. The interview also included questions on what values were important to them when making decisions about life prolongation, such as quality of life, family interests, burden on family, retaining control and independence, religious conviction, and dying with dignity.

\section{Data Analysis}

All coding during the interview was subsequently verified by listening to the audio recordings. Responses to open-ended questions were content analysed and coded from the tapes by the second and third authors, with any disagreements resolved by discussion. The audio recordings were listened to and any material regarding attitudes towards life prolonging medical technologies and the reasons underlying their views were transcribed verbatim. Analysis of the qualitative interview data was conducted with the assistance of NVivo. The transcripts were systematically analysed to identify the reasons underlying participants responses about life-sustaining technologies. The coded data were analysed using SPSS version 11. In the reported extracts, [...] 
indicates that material has been omitted, and material in brackets ( ) has been added by the authors for clarification. The extracts are referred to using an area identifier, ID number within area; and $\mathrm{M}$ or F (male or female). Thus G14-M - refers to area G, ID14, a Male participant; and A13-F refers to area A, ID13, a Female participant.

\section{Attitudes towards life prolonging medical technologies}

There was a substantial and highly significant difference in the responses of older men and women $(p<.001)$ to the initial open question: 'What are your thoughts about life prolonging medical technologies that are used to increase life span at the final stages of life?' Three-quarters of older men but only a quarter of women spontaneously indicated that they accepted the use of life-prolonging medical technologies (Table 1a). Older women were much more likely to be unequivocally opposed. In addition, more older women than men gave conflicting views, often giving nuanced answers indicating how it would depend on specific circumstances, such as the nature of the illness condition or likely resulting quality of life.

Table 1 about here

Although this initial question did not specifically ask respondents to link their views about life-prolonging technologies to themselves, four-fifths spontaneously made this linkage. Older men were significantly more likely to volunteer that they would want life-prolonging medical technologies for themselves (64\%), compared to only a third of older women, $\mathrm{p}=.023$ (Table 1b).

The majority of studies of life-prolonging medical technologies focus solely on cardiopulmonary resuscitation (CPR); our study also asked about use of a ventilator to support breathing, and artificial (or tube) feeding (Table 2). In each case, responses to the 5 point scale were recoded as 'acceptable', 'opposed' or 'intermediate' (i.e. a score of 3). More older people were in favour of CPR (51\%) than use of ventilator machines (39\%), with the lowest proportion in favour of artificial feeding (30\%). Our findings show the same rank ordering of degree of acceptance of these three lifesustaining technologies as Carmel (1999). There were consistent gender differences 
across the three procedures. In each case, older men were more in favour of these procedures than women, with a highly significant gender difference for CPR $(p=.002)$ and for ventilation $(\mathrm{p}=.011)$, but the difference was not statistically significant for artificial feeding $(\mathrm{p}=.23)$.

Table 2 about here

These findings support other studies by showing consistent gender differences, with older men more in favour of using life-prolonging medical technologies in the final stages of life, and older women more opposed. We now analyse tape-recorded qualitative data to illuminate the reasons for these gender differences among older people.

\section{Reasons for Opposition to Life-Prolonging Medical Technologies}

From analysis of the discourse of older participants, we categorised their reasons for opposition to using medical technologies at the end of life into 'other-oriented' reasons and 'self-oriented' reasons. Figure 1 provides a summary indication of the approximate frequency with which different types of reasons were articulated by older women and men, with +++ indicating a reason given by many respondents, ++ a reason given by some, and + a reason given by only one or two respondents. Older women primarily gave 'other-oriented' reasons, whereas older men primarily gave 'self-oriented' reasons for their opposition to use of medical technologies at the end of life. First, we consider those older people who gave 'other-oriented' reasons for opposing life-prolonging medical technologies.

Figure 1 about here

\section{Other-oriented reasons}

The majority of older women were opposed to use of medical technologies at the end-oflife, with most articulating 'other-oriented' reasons. Their opposition centred around the perceived burden on others of caring for them if they were severely incapacitated, as 
well as a profound sense of guilt at the thought of ever becoming a burden for their relatives.

I wouldn't want that (to be a burden).... would prefer to live in a home and hopefully they (her children) would come and visit me.... I would hate, loathe, the idea... "What to do with mother syndrome?" (F6-F)

I am conscious that my mother thinks that she is a burden... not because of her being a demanding person, but because of the needs that we have to meet.... The thought of being a burden terrifies me... (F20-F)

Sometimes yes, I think he (husband) gets a bit fed up with having to take me to the doctors. I feel a bit uncomfortable about it really. He swears under his breath... No, he doesn't say anything, I just hear him mutter. I've had it for so many years.... But I do feel guilty... (A21-F)

If I couldn't cope with myself and I was taken into hospital and that sort of thing, then I'd rather go (die), I'd... I never want to be a burden or anything, let's put it that way.

Qu: So, your attitude is....

Let me go if they know it's time... I'd prefer that... No, I don't think I'd want to live any longer than I think I ought to (A4-F)

Older men rarely spontaneously volunteered concerns about not wanting to be a burden. Later in the interview, when specifically asked if they had concerns about 'being a burden', older women had all thought about the possibility, but a number of men had not:

Not thought about (being a burden), but it would be a worry and burden to them (children). We all say we would like to go quickly. Not given (it) a lot of thought, but I would give it some thought, if I thought that it would help the family. (F13-M) 
Qu: Would you say that (the possibility of being a burden) would be important to you when considering prolonging end of life care?

Ans: I don't think so, we've got two children and both of them said they would look after us and not to worry about anything. I don't worry about that.... (A6-M)

The greater likelihood of older women voicing spontaneous concerns about not wanting to be a burden was often linked to their life course experience of caring for other family members, particularly frail and older parents.

Both my parents lingered, and my father got Alzheimer's. I would much rather he had just gone. My memories of him are in a hospice. Another lady (who respondent looks after) is confused and falling over. This is the third time, I have been through (intensive care-giving) it in the last few years, and I don't want my children to go through the same. (G7-F)

In addition, some older women had worked in nursing and care home settings, providing them with detailed knowledge of the implications of living in a severely impaired or incapacitated state. The small number of men who verbalised concerns about being a burden did so in terms of their account of previous life course experience of caring for family members.

The dominant 'other-oriented' reason for being opposed to life-prolonging medical technologies therefore revolved around the assumed implications of being a burden on others. However, a small number of older men and women stressed that there was no value in continuing to live unless they could assist others or contribute societally in some way. Another life course experience that may impact on an older person's views about life-prolonging medical technologies is experience of living in other cultures with different attitudes towards dying. The Netherlands is one of the few countries where euthanasia and physician-assisted dying is legal, which had influenced the attitudes of this older Dutch man:

As a Dutchman, we are more used to this matter. If there is no hope that a person can have a worthwhile (life), why keep the survival machine going? 
You have to have a purpose of life, it can be your presence, it requires an inter-relationship with people. If you would not be able to inter-relate any more with your equals or your children, or grandchildren or friends, could not contribute to their situation, then what the hell are you doing? I have lived in different cultures where the attitude to death is different, and it makes you think about it. (G13-M)

A small minority of women and men indicated they were opposed to use of lifeprolonging medical technologies because of financial costs of such treatments, which were considered a waste of money:

I do not agree with keeping people alive just for the sake of keeping people alive, costing such a lot, without any independent life again. (F6-F)

I do think, in some cases, that the technology has overtaken humanity. It has almost become unethical in a way, a furious amount of money is wasted on people that does not improve their quality of life at all. (G4-M)

The perception that use of life-prolonging medical technologies would not result in full recovery and therefore lead to 'being a burden' on others and the guilt that this would entail, was the major 'other-oriented' reason articulated for not wanting lifeprolonging medical technologies, which was articulated by many more older women than men. In addition, a small number of both older men and women indicated they felt there was little point in living if they could not contribute to the well-being of others, particularly their family members, or because of the high cost implications of life-sustaining care.

\section{Self-oriented reasons}

Both women and men voiced various 'self-oriented' reasons for why they would not want life-prolonging technologies, most frequently mentioning lack of dignity and the resulting poor quality of life. These two reasons were often inter-related in the discourse of older people, for example: 
I think these (medical technologies) are horrible. It is artificial, and at my age (70-74 years), I would not consider it. Depends what the quality of life is like after it, that is the important thing. Nobody should be dependent on anyone else, it (diminishes) one's dignity, that is the important thing. (G5F)

There will come a time when you wouldn't want to, when you couldn't do things for yourself, when you couldn't feed yourself, or go to the toilet... It is not dignified... I don't think that I would (like to) have tubes coming out of me, I don't think I want that. (F1-F)

Concerns about loss of dignity through using of life-prolonging medical technologies were expressed by more older women than men. Older women with close experience of the death of others following use of life-prolonging medical technologies, or of intensive caring for family members, were particularly likely to verbalise such reasons.

I am just in favour of basic procedures - a drink of water, fluid, just to keep the body (moist). Not extraordinary means, not ventilation. I would just like to die peacefully... Being a nurse, I have seen so many people, they are dying and suffering, and their life is prolonged unnecessarily, and it does not help the patient, and it does not help the families. (G20-F)

They (doctors) are obsessed these days in keeping people alive... I don't believe in euthanasia on religious grounds, but I don't believe in prolonging life if the quality of life is poor... I don't want to be kept wired up 'ever'... My husband lay like a tree trunk for weeks on end. What is the point of it all? People with Alzheimer's and that... I think it is important that they are treated and cared for properly, but if they get pneumonia, I think you should let nature take its course. (F19-F)

I would ask my children to stop it.... I wouldn't want anybody to resuscitate me or do anything about it. I think it is terrible, it happened to my mother, 
and it was just awful. I wouldn't try to resuscitate somebody who has Alzheimer's. (G2-F)

Some older men also voiced similar concerns, especially those with life course experience relating to care-giving, or who had been in certain types of occupations, such as the following man who had worked in agriculture.

No, I don't believe in it... While the person's life is good, fine, but once it has gone past that, and they don't want it, I think everybody should have the right to finish their own life... Well, I was in agriculture for many years, I think I've always felt like that, I've always, I can't see, never have seen, the sense in prolonging life of people just to... Mum had to go into hospital... and you see all these old people, just no quality - just in chairs. (A22-M)

A few older men and women indicated opposition to life-prolonging technologies because of wanting to avoid pain, being frightened of the technology or feeling that the technology was 'not natural':

For myself, at this age (age 75-79), no, I don't care if I go (die) tomorrow. Not material at my age. I just don't want pain, I am a coward... If I had a stroke and was incapacitated, I would want to go, and wouldn't want to prolong my life. I flew with the RAF during the war, I am not opposed to life prolonging measures, but I have severe qualifications. (G4-M)

(When asked about Ventilation): I think this may sound very silly, I'd hate to think of somebody putting a mask over my face and I didn't want it, that would frighten the life out of me... (A4-F)

I don't think that I would want to be (artificially fed) - I don't like the thought of giving me food another way. (F2-F)

There were also a range of other personal reasons why older people were opposed to use of life-prolonging technologies, which included the strength of their religious beliefs, that they simply felt it was the right time to die or that they felt they had already had a full life and saw no point in extending their life, especially if the result was a diminished quality of life. 
Both women and men voiced 'self-oriented' reasons for their opposition to lifesustaining medical technologies. However, as discussed earlier, older women were over twice as likely as older men to be opposed to the use of such technologies (Tables 1 and 2).

\section{Reasons for Acceptance of Life-Prolonging Medical Technologies}

This section examines what underlies men's greater acceptance of life-sustaining medical technologies for themselves. Almost all these reasons were solely 'selforiented', and related to the individual (Figure 1). A number of men, but few women, had an unquestioning faith in the success of life-prolonging medical technologies:

I would call upon anything that was proven. I don't think that I would want to be a guinea pig, but nevertheless, if it was life threatening, and you had no choice, what would it matter. (G1-M)

Because I personally enjoy life at this particular time anyway. I just want to go on living. (G16-M)

Very few older women were so overt in their desire to keep living at all costs. Some men reflected on the image of successful use of cardiopulmonary resuscitation $(\mathrm{CPR})$ in television programmes:

Only what I've seen on the telly, and in most of these hospital programmes... Well, in the case of having a heart attack or whatever, you'd want that, to be resuscitated certainly. I've known people who have been resuscitated in various ways and it's vital, yes. (A2-M)

I wouldn't mind that (CPR)... it is a first aid... you see it all in TV... the longer I am kept alive the longer my offspring could keep my pension... (F4-M)

The frequent portrayal of CPR on television and the success rates portrayed give the impression that it is a routine procedure, which has a much higher success rate than 
occurs in reality. However, it was men rather than women who tended to refer to the media portrayal in their responses.

Both older men and women who were in favour of life-prolonging technologies, often qualified this by raising concerns about quality of life, displaying an ambivalence and dilemma regarding the ultimate quality of life after use of life-prolonging technologies (Vandrevala et al. 2006).

Yeah, I mean prolonging a reasonable quality of life, then I'm in favour of that. And quite honestly if all I had to do, or all (wife) had to do, was lie on a bed in a hospital, and just being kept alive, then I wouldn't want it. But that is my view now. If I was in a situation where they said 'Right, it's that or you die', I don't know, because when the time comes apparently, we all want to cling onto life if we can. (A2-M)

The main gender difference in the types of 'self-oriented' reasons for supporting use of life-prolonging technologies was that more men expressed an unquestioning wish to continue to live, and a greater faith in the success of these technologies. The latter reflected men's more limited direct life course experience in relation to use of these technologies, and a more limited knowledge about the likelihood of satisfactory recovery following their use, particularly use of CPR. Both older women and men qualified their acceptance with a concern that the resulting quality of life should be satisfactory. However, overall fewer older women than men expressed such 'self-oriented' reasons for supporting life-prolonging technologies, which explains the two-fold gender difference found in Tables 1 and 2 .

\section{Attitudes of married older people}

Further evidence of the reasons for these gender differences can be gauged from the discourse of married men and women, when asked the same questions about lifeprolonging medical technologies. In the discourse of older married women, there was often an explicit statement of what the participant would want for themselves, which diverged from what they volunteered that they would want for their husbands, for example: 
I would probably try and resuscitate him (husband), but would not do it for myself. (F17-F)

Many older married women indicated that they would support the use of lifeprolonging medical technologies for their husbands, and care for him whatever his level of continuing disability. However, they would not want life-prolonging medical technologies for themselves, sometimes explicitly saying they would not feel it appropriate to burden their husband with their own care.

Married women were also more likely to put themselves in the mind of their husband and empathise with his wishes, than was the case for married men.

I don't think my husband would like to be a cabbage (pause) it would be shameful. (F13-F)

In their discourse, married men rarely contrasted their own views with those of their wives, and rarely said that they would prefer life-prolonging technologies for their wives but not for themselves. However, married men sometimes indicated that they were aware that their wives were opposed to life-prolonging technologies, whereas they were in favour. Married men also verbalised that their wives were more likely to have thought in detail about these issues, and had strong views about not wanting to be a burden.

\section{Discussion and Conclusions}

Even when considering fundamental issues, such as whether an individual wants lifeprolonging medical technologies for themselves, this article has shown that older women and men 'perform gender'. Women are much less likely to want life-prolonging medical technologies for themselves, particularly because of worries about being a burden on others and the guilt associated with this. This greater concern about being a burden is intrinsically linked to women's life course involvement in care-giving, both informal caring for family members and friends, and as paid carers in nursing or care work. Aspects of their life course, particularly their roles as mothers, wives and carers underpinned their responses about the use of life-sustaining medical technologies both for themselves and for significant others. Thus, women responded in terms of a 
conceptualisation of themselves in the dual roles of care-givers and care-receivers (Boneham and Sixsmith 2006).

Our findings chime with research by McPherson et al. (2007) who discuss the 'selfperceived burden' of care-recipients. Their sample of 15 patients with advanced-stage cancer were concerned about the burden they were creating for others, feeling responsibility for causing hardships to others, which resulted in personal distress. They define 'self-perceived burden' as 'empathetic concern engendered from the impact on others of one's illness and care needs, resulting in guilt, distress, feelings of responsibility, and diminished sense of self' (p 425). However, McPherson et al. do not reflect on whether 'self-perceived burden' is articulated to a greater extent by women than men in their small sample. The prominence of the discourse of fear of being a burden as a rationale for rejecting life-prolonging technologies suggests that older people themselves, especially women, has parallels with the alarmist discourse of population aging.

In our research, men were less likely to spontaneously mention any concerns about being a burden on others, and the few that did so had primarily been closely involved as carers for a relative who had died or had worked in a care-related occupation. Older men were more likely than women to be in favour of life-prolonging medical technologies for themselves, employing a discourse that primarily reflected their assumptions about how these medical technologies would affect themselves, rather than giving an account of the potential effects on others. Men had a greater faith in the success of these technologies and many simply wanted to keep living 'whatever the costs'. Men's views therefore chime more closely with the 'immortalist' rhetoric found within some anti-aging research (Settersen et al. 2008).

Our quantitative analysis of responses about life-prolonging medical technologies showed that women were not only more likely to be opposed than men, but more women gave 'conflicting views' or specified only 'under certain circumstances' in response to the initial open question about life-prolonging medical technologies (Table 1). Similarly, more women gave an 'intermediate' response regarding their attitudes towards use of CPR and ventilation (Table 2). Women's greater expression of 'conflicting views', and voicing the importance of context, reflects their more extensive and nuanced knowledge 
about health matters in general and life-prolonging medical technologies in particular, resulting in an enhanced recognition of the multiple effects of such technologies and the uncertainty of accurately assessing an individual's subsequent quality of life. Thus, women's more ambivalent responses indicate that they were more likely to weigh up both benefits and disadvantages, reflecting the dilemmatic nature of a consideration of life-prolonging technologies in relation to long-term effects on quality of life (Vandrevala et al. 2006).

We suggest that these gender differences in attitudes towards life-prolonging medical technologies relate to three sets of gender-linked factors. First, a person's life course experience influences the ways in which they respond to questions about lifesustaining technologies. Extensive research on the provision of informal care has shown that women are more likely to be care-givers for family members, especially intensive 'round-the-clock' care-giving (Arber and Ginn 1995, Maher and Green 2002). This life course experience of women forms part of the backcloth that women draw on when considering their own decision-making about end-of-life care. In addition, during their life course women are more likely to have been paid workers in care settings, such as nurses and care workers in hospitals and care homes, thus obtaining a detailed understanding of the implications of using life-prolonging medical technologies. The minority of older men with life experience of caring were also more likely to voice opposition to receiving life-prolonging medical technologies.

Second, women are more knowledgeable than men about health matters (Blaxter 1990, Courtenay 2000), more likely to be interested in and concerned about health issues, and more likely to discuss health issues with friends and family members (Davidson and Arber 2004, Calasanti 2004). Older women talk extensively about health matters to each other on an everyday basis, relying on social networks for health expertise (Boneham and Sixsmith 2006). Women are therefore more likely to be knowledgeable about life-sustaining medical technologies, including the success rates of such technologies and the potential adverse effects of their use. For example, use of cardiopulmonary resuscitation at the end of life has a very low success rate; Murphy et al. (1989) report figures of only $4 \%$ of patients leaving hospital alive with no serious adverse effects, and other studies confirm low success rates (Karetzky et al. 
1996; Conway et al. 2006). Whereas, men were more likely to rely on TV and film portrayals of successful (and often routine) use of CPR to inform their attitudes.

Finally, women empathise to a greater extent with how receiving life-sustaining medical technologies will impact on the life of their loved ones, and display a deeper understanding and perception of the views and feelings of their family members regarding use of such medical technologies. This corresponds with the extensive literature showing that women are more engaged in the provision of emotional labour (James 1989, Williams 2002, Hochschild 2003). Mason (1996) argues that women are more likely to engage in 'sentient activity', with women unconsciously orienting their actions towards the needs and emotional well-being of another person (especially their children or partner), rather than privileging their own needs.

In our research, some older married women participants reflected on the implications of using medical technologies for their husband, even though the interview focused on themselves and their own wishes about life-sustaining technologies. These older women empathised with the wishes of their husband, considering in detail the effects of undergoing life-prolonging technologies and the implications of any residual disability on their partners' subsequent quality of life. Women were more likely to voice concerns about preserving the identity of the other person. This illustrates how the performance of gender and differential life experiences pervade a consideration of even these most fundamental aspects of life and death.

The authors acknowledge that gendered identities are not fixed and may be presented differently in varying circumstances. Our findings show some similarities in the discourse of older women and men about reasons underlying their views about lifesustaining technologies, as well as gender differences. We do not wish to reify gender differences as if they are monolithic and immutable (Seale et al. 2006), but emphasise that gender differences are located within the life course of older women and men and their differential experiences, roles and identities within the family.

The sample of older participants was equally balanced in terms of age-sex groups, facilitating comparison of gender differences. Since the sample was recruited through general practitioner age-sex registers, rather than volunteers or an opportunistic sample, 
this potentially provides a more representative sample of older people living in the community. However, a limitation is the low response rate $(30 \%)$, which potentially reduces sample representativeness. The low recruitment rate may suggest that many older people view the subject of death and dying as too distressing to discuss, with our findings limited by our ability to only evaluate the attitudes of those who were willing to participate.

There is increasing health policy concern to encourage end-of-life planning, which advocates that patients should express their views in advance about use of life-sustaining medical technologies at the end-of-life (Rodriguez and Young 2006, Carr and Khodyakov 2007). However, the debate to date has conceptualised patients in an individualistic way, as autonomous individual decision-makers. Our findings suggest that there are strong gendered patterns in desire for life-sustaining treatments such as resuscitation, which reflect gendered norms and values, with women much more likely to consider the effects of their own potential resuscitation on others, rather than on themselves. An implication of our findings, based on the views of older people themselves, is that life-sustaining technological interventions may in future be attempted to a greater extent on men than on women with the same severity of health condition. It is important for health practitioners, as well as sociologists, to consider the implications of what may ultimately produce a profound gender inequality at the end stages of life.

Our research has shown that one social factor, namely gender, has a major effect on attitudes and thereby decision-making about use of life-prolonging technologies. Other characteristics of older people may equally influence such attitudes potentially leading to fundamental social inequalities. Researchers interested in anti-aging should fully consider the attitudes and views of older individuals about specific anti-aging technologies, and how these intersect with cultural understandings and broader social inequalities. The rhetoric of choice and individualism may blind researchers and policy makers to the potential social, including gender, inequalities that may emanate from greater development and availability of anti-aging medical technologies. There is a need to heed the voices of older people themselves, alongside those of anti-aging practitioners and researchers. 


\section{Acknowledgements}

The research was supported by a grant from the Nuffield Foundation, UK. The authors are indebted to all the participants and organisations for their interest in supporting this study. 


\section{References}

Arber, S. and Ginn, J. 1995. Gender differences in informal caring, Health and Social Care in the Community, 3: 19-31.

Blaxter, M. 1990. Health and Lifestyles, London: Routledge

Boneham, M.A. and Sixsmith, J. A. 2006. The voices of older women in a disadvantaged community: Issues of health and social capital, Social Science and Medicine, 62: 269-279.

British Medical Association. 2001. Decisions relating to cardiopulmonary resuscitation. A join statement from the British Medical Association, Resuscitation Council, UK and the Royal College of Nursing. http://www.resus.org.uk/pages/dnar.htm (accessed on 09/04/2004).

Calasanti, T. 2004. Feminist gerontology and old men, Journal of Gerontology, 59B (6): 305-314.

Carmel S, 1999. Life-sustaining treatments: what doctors do, what they want for themselves and what elder persons want, Social Science and Medicine, 49: 1401-1408.

Carmel, S. 2001. The will to live: gender differences among elderly patients, Social Science and Medicine, 52: 949-958.

Carr, D. and Khodyakov, D. 2007. End-of-life health care planning among young-old adults: An assessment of psychosocial influences, Journal of Gerontology, 62B(2): S135-S141.

Conway, S.P., Luxton, T., Dingwall, R., Harwood, R.H. and Gladman, R.F. 2006. Cardiopulmonary resuscitation in continuing care settings, British Medical Journal, 332: 479-482.

Courtenay, W.H. 2000. Constructions of masculinity and their influence on men's wellbeing: A theory of gender and health, Social Science and Medicine, 50: 1385-1402.

Davidson, K. and Arber, S. 2004. Older men: Their health behaviours and partnership status. In Walker, A. and Hagan Hennessey C. (eds) Growing Older: Quality of Life in Old Age. Maidenhead: Open University Press.

Ditto, P.H., Smucker, W.D., Danks, J.H., Jacobson, J.A., Houts, R.M., Fagerlin, A., Copploa, K.M. and Gready, R.M. 2003. Stability of older adults' preferences for lifesustaining medical treatment, Health Psychology, 22: 606-615.

Duffield P. and Podzansky, J. E. 1996. The completion of advance directives in primary care, Journal of Family Practice, 42: 378-384.

Garnett, D., Vandrevala., T., Hampson, S.E., Daly, T. and Arber, S. 2008. Family members' perspectives on potential discussions about life prolongation for their older relatives, Mortality 13 (1): 65-81. 
Gunasekera, N.P.R., Tiller, D.J., Clements, L.T.S. and Bhattacharya, B.K. 1986. Elderly patients views on cardiopulmonary resuscitation. Age and Ageing, 15: 364368 .

Hochschild, A. 2003. The Second Shift, London: Penguin.

James, N. 1989. Emotional labour: Skill and work in the social regulation of feelings, Sociological Review, 37 (1): 15-42.

Karetzky, M., Zubair, M. and Parikh, J. 1996. Cardiopulmonary resuscitation in intensive care unit and non-intensive care unit patients. Immediate and long-term survival, Archives of Internal Medicine, 155 (12): 215-6.

Lo, B., Saika, G. and Strull, W. 1985. Do not resuscitate decisions. A prospective study at three teaching hospitals. Archives of Internal Medicine, 145: 1115-17.

Maher, J. and Green, H. 2002. Carers 2000 National Statistics, London: The Stationery Office.

Malloy, T.R., Wigton, R.S., Meeske, J., and Tape, T.G. 1992. The influence of treatment descriptions on advance medical directive decisions. Journal of American Geriatric Society, 40: 1255-60.

Mason, J. 1996. Gender, care and sensibility in family and kin relationships. In Holland, J. and Adkins L. (eds) Sex, Sensibility and the Gendered Body. Basingstoke: Macmillan.

McPherson, C.J., Wilson, K.G., and Murray, M.A. 2007. Feeling like a burden: Exploring the perspectives of patients at the end of life, Social Science and Medicine, 64: 417-427.

Murphy, D.J., Murray, A.M., Robinson, B.E. and Campion, E.W. 1989. Outcomes of cardiopulmonary resuscitation in the elderly, Annals of Internal Medicine, 111 (3): 199205.

Mykytyn, C.E. 2008. Optimization and process at the crossroads of nature and disease in anti-aging medicine, Journal of Aging Studies [insert volume, page numbers]

Phillips, R.S., Wenger, N.S., Teno, J., Oye, R.K., Younger, S., Califf, R., Layde, P., Connors, A.F. and Lynn, J. 1996. Choices of seriously ill patients about cardiopulmonary resuscitation: Correlates and outcomes. The American Journal of Medicine, 100: 128-137.

Rodriguez, K. L. and Young, A.J. 2006. Patients' and healthcare providers' understandings of life-sustaining treatments: Are perceptions of goals shared or divergent? Social Science and Medicine, 62: 125-133. 
Schonwetter, R.S., Walker, R.M., Kramer, D.R., \& Robinson, B.E. 1994.

Socioeconomic status and resuscitation preferences in the elderly. Journal of Applied Gerontology, 13 (2): 157-171.

Seale, C. and Addington-Hall, J. 1995. Dying at the best time, Social Science and Medicine, 40(5): 589-595.

Seale, C., Ziebland, S. and Charteris-Black, J. 2006. Gender, cancer experience and internet use: A comparative keyword analysis of interviews and online cancer support groups, Social Science and Medicine, 62 (10): 2577-2590.

Settersten, R.A., Flatt, M.A. and Ponsaran, R. 2008. From the lab to the front line: How individual biogerontologists navigate their contested field, Journal of Aging Studies [insert volume, page numbers]

Seymour, J.E., Gott, M., Bellamy, G., Ahmedzai, S. and Clark, D. 2004. Planning for the end-of-life: the views of older people about advance care planning. Social Science and Medicine, 59 (1): 57-68.

Vandrevala, T., Hampson, S.E., Daly, T., Arber, S. and Thomas, H. 2006. Dilemmas in decision-making about resuscitation: A focus group study of older people, Social Science and Medicine, 62: 1579-1593.

Vincent, J. 2006. Ageing contested: Anti-aging science and the cultural construction of old age, Sociology, 40(4): 681-698.

West C. and Zimmerman, D.H. 1987. Doing gender, Gender Studies, 1 (2): 125-151.

Williams, C. 2002. Mothers, Young People and Chronic Illness, Aldershot: Ashgate Press. 
Table 1. Attitudes towards Life-Prolonging Medical Technologies by Gender of the Older Person (Column percentages)

(a) General attitudes ${ }^{\text {a }}$

Accept

Conflicting views/under certain circumstances

Opposed

$\mathrm{N}=$

Significance

(b) Related to themselves ${ }^{\text {b }}$

Wants Life Prolongation

Against Life Prolongation

$\mathrm{N}=$

Significance
Male Female

\section{All}

$\begin{array}{ccc}73 & 25 & 48 \\ 12 & 36 & 25 \\ 15 & 39 & 27 \\ 100 \% & 100 \% & 100 \% \\ 33 & 36 \quad \mathrm{P}=.000 & 69 \\ & & \end{array}$

64

33

47

36

67

53

$100 \%$

$100 \%$

$100 \%$

25

30

55

a Coded from response to initial open question: What are your thoughts about Life Prolonging Medical Technologies that are used to increase life span at the final stages of life?

b Coded from above open question, where participant spontaneously mentioned they wanted or were against Life Prolonging Medical Technologies for themselves. NB. A fifth of the sample did not spontaneously mention themselves, and therefore are excluded from (b) 
Table 2. Acceptability of Three Life-Prolonging Medical Technologies by Gender of the Older Person (Column percentages ${ }^{\mathrm{a}}$ )

(a) Cardiopulmonary Resuscitation (CPR)

Acceptable

\begin{tabular}{ccc} 
Male & Female & All \\
& & \\
73 & 31 & 51 \\
18 & 39 & 29 \\
9 & 31 & 20 \\
$100 \%$ & $100 \%$ & $100 \%$ \\
33 & 36 & 69 \\
\multicolumn{4}{c}{$\mathrm{P}=.002$} \\
58 & 22 & 39 \\
21 & 36 & 29 \\
21 & 42 & 32 \\
$100 \%$ & $100 \%$ & $100 \%$ \\
33 & 36 & 69 \\
\multicolumn{2}{c}{$\mathrm{P}=.011$}
\end{tabular}

Significance, $\mathrm{p}=$

Neutral

Opposed

$\mathrm{N}=$

Significance, $\mathrm{p}=$

(b) Use of Ventilator Machine for Breathing

Acceptable

Neutral

Opposed

$\mathrm{N}=$

(c) Artificial (Tube) Feeding

Acceptable

39

$\begin{array}{ll}22 & 30\end{array}$

Neutral

30

$31 \quad 30$

Opposed

30

$100 \%$

47

39

$\mathrm{N}=$

33

$100 \%$

$100 \%$

Significance, $p=$

$36 \quad 69$

$\mathrm{P}=.23$ (ns)

a Not all percentages sum to $100 \%$ because of rounding

b Recoded from a 5 point scale: 1 Very acceptable to 5 Highly Opposed (Codes 1 and 2 - Acceptable; code 3 - Neutral; Codes 4 and 5-Opposed) 
Figure 1 Reasons for Attitudes ${ }^{a}$ to Life-Prolonging Medical Technologies by Gender

\section{Women Men}

\section{$\underline{\text { Reasons for Opposition: }}$}

\section{Other-oriented}

Burden on others, guilt at being a burden

If can no longer contribute to the wellbeing of others

$\begin{array}{ll}+++ & + \\ + & + \\ + & +\end{array}$

Self-oriented

No dignity

Results in no Quality of Life

Want to avoid pain, suffering

A time to die, religious reasons, had own life

$\begin{array}{ll}++ & + \\ ++ & ++ \\ + & ++ \\ + & +\end{array}$

\section{Reasons for Acceptance:}

\section{Self-oriented}

Good experience of others with life prolonging technologies $+\quad++$ Want to live life to the full, never give up hope ++ If good Quality of Life for self

$++\quad++$

\section{Life Course Experiences impacting on articulation of above reasons}

Experiences of caring for older family members

$\begin{array}{ll}+++ & + \\ ++ & + \\ + & + \\ + & +\end{array}$

Paid work involving care for older people

$+$

Own personal health care experiences

$+$

Strength of religious faith and beliefs

Experience of death and dying in other cultures

$+$

$+$

a +++ indicates a reason by many respondents, ++ a reason given by some, and + a reason given by only one or two respondents. 